\title{
Demandas decorrentes da inclusão escolar
}

\author{
Selma Norberto Matos* \\ Eniceia Gonçalves Mendes**
}

\section{Resumo}

Com a implementação das políticas públicas em inclusão escolar, particularmente aquelas voltadas para o público- alvo da educação especial, cresce o número de alunos com Necessidades Educacionais Especiais (NEEs) em classes comuns, fato que ajuda a compor um cenário nas escolas que tem desvelado limitações e contradições do sistema educacional brasileiro. Atores e autores educacionais são desafiados a construir saberes capazes de responder às demandas do cotidiano escolar relacionadas à convivência e aprendizagem na diversidade. Considerando que este processo inclusivo é novo nas escolas, o estudo teve como objetivo analisar as demandas dos professores decorrentes da inclusão escolar. A pesquisa foi qualitativa do tipo exploratório, participando seis professoras, seus alunos com NEEs e três profissionais do Núcleo de Educação Inclusiva da Secretaria Municipal de Educação. Para coleta de dados, foram utilizados: técnica de observação participante, diário de campo, entrevista semiestruturada, questionário e, para discussão dos dados, análise de conteúdo. Os resultados indicam que existem conquistas e contradições na realidade das escolas que se propõem inclusivas; avanços e limitações resultantes da política municipal, e que o modelo de atuação da equipe de educação especial, no contexto analisado, pode ser revisto ou ampliado. Indicam que os professores apresentam demandas no domínio da política pública, da formação, e demandas dirigidas ao psicólogo.

Palavras-chave: Educação Especial; Inclusão escolar; Demandas de Professores.

* Docente da Uiversidade Estadual do Sudoeste da Bahia. Salvador, Bahia, Brasil.

** Professora associada da Universidade Federal de São Carlos, São Carlos, São Paulo, Brasil. 


\section{Demands from the school inclusion}

\section{Abstract}

From the implementation of public policies on school inclusion, mainly those directed to the target audience of special education, the number of students with special educational needs in common classes has increased. This fact has helped to compose the picture in schools where the limitations and contradictions of the Brazilian educational system have appeared. Educational actors and authors are challenged to build knowledge able of responding to demands of daily school, concerning living and learning in diversity. Whereas this inclusive process is new in the schools, the study aimed to analyze the demands of teachers from the school inclusion. The research was qualitative and exploratory, and six teachers, their students with special educational needs and three professionals in the Nucleus of Inclusive Education from the Municipal Department of Education took in it. Technique of participant observation, field diary, semi-structured interview and questionnaire were used for data collection, while analysis of content was used for discussion of the data. The results indicate that there are achievements and contradictions in the reality of schools that themselves propose inclusive; advances and limitations resulting from the municipal politics; that the model of performance of the group of special education, in the context analyzed, may be revised or expanded; and that the teachers has demands with regard to public policy, training, and the psychologist.

Keywords: Special Education; School Inclusion; Demands of teachers.

\section{Introdução}

A perspectiva de escolarização de crianças e jovens com Necessidades Educacionais Especiais (NEEs) nas classes comuns do ensino regular é hoje um imperativo moral e político, sendo possível reconhecer que a recente conquista da facilidade de acesso do público-alvo da educação especial à escola configura-se como um momento ímpar na história brasileira. Defende-se a inclusão escolar como um princípio filosófico e como um processo marcado por muitas contradições, em que se avança em relação à igualdade de oportunidades, ao direito à diversidade e à escolarização dos sujeitos da educação especial.

Nas últimas décadas, tanto na legislação mais ampla, quanto nas políticas educacionais, foi intensa a ação do governo federal em prol de uma educação inclusiva, direcionada à garantia dos direitos de diversos segmentos sociais historicamente excluídos. Na área de educação especial, este evidente destaque também é resultado da mobilização das organizações civis, ligadas direta ou indiretamente às questões que afetam as pessoas com deficiência (LIMA; MENDES, 2008). Dados do Censo Escolar 2010 apontam 702.603 matrículas da educação especial, 75,8\% dessas efetivadas nas escolas públicas, sendo possível encontrar 218.271 alunos com NEEs nas classes e escolas especiais e 484.332 nas classes comuns (BRASIL, 2010). Analisando as recentes legislações e os dados oficiais, observa-se que permanecem tanto a escassez de 
oferta de serviços para atender a estimativa de 6 milhões de pessoas com deficiência, sendo 3 milhões em idade escolar, como o insucesso no desempenho escolar dessa clientela e o incentivo explícito à iniciativa privada que, ainda hoje, é responsável por parcela significativa das matrículas (MENDES et al, 2010a).

Teóricos evidenciam dificuldades das mais variadas ordens para implantação de um sistema educacional inclusivo no Brasil, relacionadas seja à organização da sociedade, seus valores hegemônicos, seja aos meios concretamente disponibilizados para sua efetivação (CARVALHO, 2004; FERREIRA, 2006; MENDES, 2010). Mendes (2006) faz algumas críticas às propostas oficiais dos últimos anos, particularmente às tentativas do governo de impor uma única concepção de política de inclusão quando não há consenso entre os estudiosos da área.

Diante da necessidade de escolarizar alunos com NEE em classes comuns do ensino regular, alguns dos principais desafios enfrentados pelos atores educacionais no cotidiano escolar são: a formação de professores (MENDES, 2002, 2008, 2010; FREITAS, 2008; JESUS, 2008), a convivência com a diversidade (PEREIRA; ANDRADE; ANJOS, 2009; CARVALHO, 2000) e a relação família-escola (COLNAGO, 2008). A realidade revela também que as escolas são espaços contraditórios, nos quais existem práticas de discriminação e conscientização e, que ainda se encontram distantes do que preconizam os documentos oficiais sobre inclusão escolar.

É, nas condições históricas, políticas e socioculturais descritas em que se constituem as solicitações dos diversos atores escolares aos especialistas e estudiosos da área educacional. Nessa perspectiva, foi desenvolvida uma pesquisa durante $\mathrm{o}$ Mestrado em Educação Especial na UFSCar (2010/2012) com o objetivo de analisar as demandas decorrentes da educação inclusiva e as possibilidades de atuação do psicólogo escolar, sendo, o presente trabalho, um recorte referente à análise das demandas.

\section{Desenvolvimento}

A pesquisa baseou-se em uma abordagem qualitativa do tipo exploratória. O estudo foi desenvolvido em três escolas de uma cidade do interior baiano, que se tornou o município pólo do Programa Educação Inclusiva: direito à diversidade, em 2005. A rede municipal de ensino possuía, no ano de 2010, 203 unidades escolares, em cujas salas estudam 41.199 alunos, sendo 633 com NEEs matriculados nas classes comuns do ensino regular e 544 no ensino fundamental. A Secretaria Municipal de Educação (SMED) sistematizou os princípios orientadores da Educação Especial em um documento intitulado Diretrizes para a Educação Inclusiva (PMVC, 2007). E, em 2010, a SMED possuía um Núcleo de Educação Inclusiva e oferecia o Atendimento Educacional Especializado (AEE) em 11 salas de recursos multifuncionais.

Essa pesquisa teve como participantes diretos seis professoras de classes comuns dos anos iniciais do ensino fundamental que trabalhavam junto a alunos com 
NEEs (PA; PB; PC; PD; PE; PF) e, como participantes indiretos os referidos educandos e os profissionais do Núcleo de Inclusão da SMED.

Todos os participantes eram professoras mulheres, que tinham uma média de 29 alunos por sala; a faixa etária variou entre 33 a 40 anos de idade; três professoras tinham menos de quatro anos de serviço na SMED e as outras mais de 10 anos; quatro educadoras eram pedagogas, duas destas especialistas em áreas da educação; três professoras participaram de cursos de curta duração na área de educação especial oferecidos pela SMED, uma fez curso de longa duração (Língua Brasileira de Sinais) e duas não tiveram capacitação na área. O período de experiência das educadoras junto alunos com NEE variou de quatro meses a três anos.

Foram respeitados os critérios da SMED na definição dos alunos que apresentavam NEEs e assim participaram do estudo: um aluno com Deficiência Intelectual, um aluno com Paralisia Cerebral, sem comprometimento cognitivo, um aluno com Deficiência Auditiva, um aluno com Autismo, um aluno com Deficiência Múltipla, e um aluno com Transtorno do Déficit de Atenção e Hiperatividade. O Núcleo de Educação Inclusiva, em 2010, era composto de duas psicólogas, uma delas também licenciada em ciências biológicas, e uma pedagoga, todas com especialização, sendo duas destas em AEE; o tempo de serviço na Secretaria variava de três a dez anos.

Para coleta de dados foram utilizados: um roteiro de entrevista semiestruturada e observação participante, dirigidas aos professores; diário de campo (DC); questionário para os profissionais do Núcleo contendo questões relativas ao seu funcionamento e atuação; questionário para os diretores a fim de caracterizar as escolas.

No que se refere aos procedimentos de coleta de dados, a primeira etapa do estudo foi destinada aos procedimentos éticos, seguidos de reuniões com profissional do Núcleo para obter dados que permitissem mapeamento educacional da rede e caracterização dos alunos considerados com NEEs. A escolha das escolas participantes teve como critérios: atender os anos iniciais do ensino fundamental e possuir grande diversidade categorial de alunos com NEE matriculados. Posteriormente, foi feito contato com diretores escolares para identificação das classes, dos professores e alunos que atendessem aos critérios de participação na pesquisa. As educadoras interessadas assinaram o Termo de Consentimento Livre e Esclarecido (TCLE) e agendaram a data e o local da entrevista. O contato inicial com os pais ou responsáveis pelos alunos com NEE foi feito pelas professoras e, posteriormente, pela pesquisadora, que assegurou a assinatura do TCLE. Após realização de todas as entrevistas, iniciaram-se as observações, objetivando complementar dados a respeito das demandas e investigar in loco quem eram os alunos com NEE. Foram realizadas duas rodadas de observações, num total de doze, sendo duas observações em cada sala de aula, com duração de, aproximadamente, quatro horas cada uma. O intervalo entre cada rodada de seis observações foi de 20 a 25 dias. Por fim, os questionários foram entregues às diretoras e foi solicitada autorização à Administração Escolar para aplicação de questionário aos profissionais do Núcleo de Educação Inclusiva, com cópias do TCLE anexadas. 
Quanto aos procedimentos de análise, as entrevistas inicialmente registradas em áudio foram transcritas. Foram analisadas: as respostas dos profissionais do Núcleo e dos diretores às questões formuladas nos questionários; as respostas das professoras às entrevistas; e os registros das observações nos diários de campo. Os dados obtidos foram submetidos à análise de conteúdo de Amado (2000).

\section{Resultados}

Com a leitura extensiva dos dados obtidos nas entrevistas feitas aos professores, observações em salas de aula e questionários, foram identificados três grandes eixos temáticos, em função do conteúdo principal das demandas, a saber: demandas no domínio das políticas públicas; demandas no domínio da formação, e demandas especificamente dirigidas ao psicólogo escolar.

\section{Categorias e subcategorias do eixo 01: demandas dos professores no domínio das políticas públicas}

Considerando o eixo temático Demandas no domínio das políticas públicas, os professores municipais de Vitória da Conquista, ao apresentarem suas demandas, evidenciaram algumas contradições na atual política nacional e municipal de inclusão e a distância entre as proposições e a realidade escolar. Nesse eixo, surgem quatro categorias e suas respectivas subcategorias. Estas serão exemplificadas e analisadas a seguir.

Espaço e cultura escolar: mudar a estrutura física da escola; adquirir material pedagógico; implantar cultura de trabalho colaborativo na escola para acompanhamento

[...] e a locomoção da criança dentro da escola, que não tem tudo adaptado para ela, então muitas vezes isso é uma barreira, porque, por exemplo, tem escola que no banheiro não tem aquele corrimão para ela se apoiar. (PB)

[...] Por exemplo, eu vou chegar na sala com meus meninos e vou trabalhar com eles hoje multiplicação, mas eu tenho meus meios, eu tenho livro, eu tenho meu jogo, eu tenho alguma coisa pra eu trabalhar com eles, e com ela (AB)? Se eu não tenho materiais adequados, recursos didáticos pra ela? (PB)

[...] Outra barreira também: precisamos de reuniões para sanar as dificuldades, as necessidades do alunado em si, de todos, não é só eu com a direção, mas dos professores com a direção, uma reunião coletiva pra falar do alunado, do que está dando certo, pra falar assim, lá na minha sala estou fazendo isso, e isso e está dando certo. (PD)

Os dados indicam a perpetuação das desigualdades, no que se refere à acessibilidade, e que há demanda pela construção de uma cultura colaborativa nas escolas, evidenciam, também, que as oficinas para produção de material realizada 
pela SMED não têm suprido a demanda dos professores das salas comum e que estes não têm tido acesso aos recursos das salas multifuncionais, presentes em duas das escolas investigadas.

\section{Contratação de pessoal: contratar profissionais especializados; contratar cuidadores e auxiliares de sala}

[...] A gente já recebe essas crianças na escola, a gente quer fazer um trabalho que contemple todos em sala de aula, mas não existe esse apoio de profissionais especialistas, que nos oriente no dia a dia do trabalho com esta criança em sala de aula, pra que a gente não atrapalhe, não exclua os outros alunos. (PE)

[...] Salas super lotadas, falta de auxiliares, no caso de AA ela tem uma cuidadora, mas os outros, não. Eu não estou preparada. (PA)

Os educadores sentem necessidade de auxiliares e orientações mais sistemáticas dos especialistas a fim de qualificarem sua atuação profissional e, cobram da SMED maior investimento neste setor com intuito de evitar a exclusão dos alunos com NEEs nas salas de aula.

\section{Política de gestão de pessoal: formação continuada de professores; definir papéis e responsabilidade de professores e cuidadores; e melhorar as condições de trabalho dos professores}

[...] é preciso incluir a preparação contínua do professor para estar recebendo este aluno (com NEE) com cursos, encontros, pra se passar experiências, porque talvez minha experiência não é a mesma de minha colega, sob responsabilidade da SMED, em primeira instância, depois dos governantes, da união. (PA)

[...] Pergunto à professora se chegou a planejar e pensar em alguma adaptação das atividades do dia para a aluna, e a professora (PD) diz claramente: "as atividades de AD, esta parte, quem fica mais é a cuidadora”. (DC2 10/05/2011)

Eu acho que as autoridades, olha bem, eu gostaria assim, quando o professor tivesse alunos especiais que recebesse mais, porque dá trabalho, salas..., diminuir as turmas para facilitar a atenção, e um aumento na remuneração, as turmas são enormes. (PD)

Há demandas decorrentes do confronto entre as necessidades profissionais dos educadores e as proposições ou modo de atuação da política municipal. Os dados evidenciam que os professores reconhecem dificuldades oriundas das limitações em sua formação inicial e que os cursos oferecidos pelo poder público têm sido insuficientes ou mesmo inadequados à sua realidade, confirmando as análises de Mendes (2006; 2010) e Lago (2010). O desconhecimento das funções e responsabilidades dos diversos profissionais da escola evidenciam o nível de fragmentação na gestão e organização dos sistemas educacionais e as falhas daí decorrentes, como sinaliza Siems (2010). Observa-se também expectativas de interlocução dos educadores com os pro- 
fissionais do Núcleo de Educação Inclusiva, a escassa presença destes nas escolas e o fato de que os professores não têm controle nem gerenciam seu tempo no contexto escolar. Sabe-se que as condições de trabalho fazem parte do processo de profissionalização do educador (SIEMS, 2010) e,' a melhoria destas condições deve compor uma política de gestão de pessoal que se preocupa em reverter o processo de proletarização da docência, em busca da qualidade da educação.

\section{Melhorar diretrizes para a Política de Inclusão: definir concepções e objetivos para a política de inclusão escolar; definir indicadores de acompanhamento da política de inclusão escolar; definir a função da escolarização para alunos com NEE; precisar melhor a população alvo da política de inclusão escolar}

[...] não está claro para mim, se esta inclusão é só a parte social ou se esta inclusão permeia pelo pedagógico também, pelo desenvolvimento dessa criança. (PA)

[...] precisa mais acompanhamento da Secretaria de Educação, com psicólogos. Não estou falando que o psicólogo tem que ficar plantado aqui na escola, eu to falando de acompanhamento: "o aluno é assim". Eu tenho que saber como o aluno está, com o relatório que eu faço, ai tem o relatório da sala de recursos multifuncional, que também tem o relatório que faz, a Secretaria de Educação, tem Psicólogo lá, que tem que está a par, pra dar o suporte para gente aqui, e para os meninos. (PD)

[...], tem alunos que não da pra ficar na sala do ensino regular por que tem aluno que precisa de um ambiente que realmente tenha conhecimento geral do que passa com ele, em casos extremos; agora tem muitas pessoas que vivem isolados, que são anuladas, a margem da sociedade, que hoje se chama de especiais, que tem condições de estar. [...] Mas no caso extremo do aluno assim violento, ai não, ai precisa ter critérios, ai seria outro espaço, outra escola, a não seria uma escola regular. (PF)

Os professores apresentam dúvidas conceituais, falta de clareza e indagações relevantes sobre a política. O desconhecimento de marcos legais e das bases teóricas, que sustentam as propostas de inclusão escolar, aprofunda a alienação do trabalho pedagógico e consolida a busca, quase desumana, de significado e de sentido pessoal de que nos fala Rocha e Souza (2008). As expressões e adjetivações utilizadas pelos educadores para se referirem à clientela da educação especial evidenciam, mais que a necessidade de mudança no uso da nomenclatura, a demanda por uma definição mais clara desta população. A definição da clientela da educação especial modificase ao longo da história nas legislações e políticas educacionais (FERREIRA, 2006) e mais recentemente, a Resolução CNE/CEB 4/2009 busca esclarecer que esses sujeitos são os alunos com deficiência, com transtornos globais do desenvolvimento e aqueles com altas habilidades/superdotação (BRASIL, 2009). No entanto, observa-se ainda a ausência de indicadores claros para avaliação da população com deficiência intelectual (DI) e falta de diretrizes acerca do por quem e como os alunos com NEE devam ser avaliados e identificados, o que pode dificultar o acompanhamento da política a nível nacional. Na vasta produção bibliográfica brasileira coabitam diferentes leitu- 
ras sobre a deficiência intelectual que resultam em diversos modos de se relacionar e nas possibilidades de se escolarizar os alunos identificados nesta categoria (BRIDI; BAPTISTA, 2012). Estão presentes as propostas avaliativas que utilizam procedimentos mensuráveis e padronizados (VELTRONE, 2011), e outras que privilegiam os processos, as interações e as relações sociais, com base nas contribuições da abordagem histórico-cultural, em especial de Vygotsky (ANACHE, 200l; ANACHE; MITJÂNS, 2007; BRIDI; BAPTISTA, 2012). A literatura aponta, como desafio atual, a construção de outras avaliações capazes de oferecer informações sobre os processos de aprendizagem das pessoas com DI.

\section{Categorias e subcategorias do eixo 2: demandas dos professores no domínio da formação}

Os resultados do presente estudo evidenciaram que uma das principais demandas dos professores em exercício decorrente da inclusão escolar continua sendo a formação, mesmo por parte daqueles que participaram dos cursos oferecidos pelo Programa Educação Inclusiva: direito à diversidade, corroborando com os achados da literatura na área (MENDES, 2002, 2008, 2009; FREITAS, 2008; JESUS, 2008; MIRANDA, 2009; LAGO, 2010). No eixo temático Demandas no domínio da formação, surgem três categorias e suas respectivas subcategorias

Desenvolvimento de Habilidades interpessoais: como intensificar trocas sociais e melhorar qualidade da relação com o aluno com NEE; como preparar os colegas; como lidar com o preconceito dos colegas; como assegurar igualdade de direitos e deveres em classe respeitando as diferenças; como trabalhar colaborativamente com a cuidadora; como lidar com as famílias.

[...] A professora (PA) não se dirigiu a ela (AA) em nenhum momento durante toda a tarde. (DC123/03/2011)

[...] a professor (PD), ao encorajá-la (AD), fala como se estivesse tratando com uma criança bem mais nova que os demais da classe. (DC210/05/2011)

[...] Os colegas mostram-se bastante curiosos sobre suas atividades e materiais diferenciados e seus comportamentos incomuns, principalmente quando é agressiva ou quando desarruma materiais Mas ninguém, nem PD conversa nada em classe sobre o que ocorre. (DC210/05/2011)

[...] No momento do lanche, AF come sozinho, ao mesmo tempo que os colegas, mas, ao terminar de guardar seu copo e prato, AF não espera o restante da turma, e a professora (PF) permite que ele saia para o pátio, junto com a cuidadora, antes de autorizar o restante da classe. (DCl01/04/2011)

Os dados evidenciam que há estudantes os quais permanecem isolados em classe, outros que interagem apenas com a cuidadora e, existem os que vivenciam situações de superproteção e infantilização. As professoras sentem dificuldade para conversar em classe sobre as características dos alunos com NEEs e, para justificar o trabalho diferenciado junto a esta clientela. Por outro lado, raramente professores e 
cuidadoras $^{2}$ dialogam, pois não existe planejamento ou avaliação conjunta, embora existam divergências sobre o modo de intervirem junto a alunos com NEEs. Além disso, professores querem construir relações colaborativas com os pais para superarem representações negativas das pessoas com NEEs.

\section{Demanda por conhecimento sobre o aluno: obter informações prévias sobre a condição do aluno com NEE}

[...] Eu acho que existe, sim, com relação à capacitação do profissional, pra não fazer como eu, chegar aqui e me deparar com uma criança e não saber como trabalhar com essa criança, não ter meios, não ter fontes para trabalhar com essa criança. Por exemplo: se a matricula é feita de dezembro a março com os alunos da casa, poderia o quê? Saber qual o professor que vai ficar com aquela criança e providenciar logo uma capacitação sobre aquela criança, porque a rede já tem conhecimento do problema que ela tem. (PB)

Os professores sabem que quanto mais conhecerem seus educandos, maiores condições terão de se prepararem emocional e pedagogicamente para o desafio da inclusão escolar. Para promover o desenvolvimento de novas funções e sistemas psíquicos, que permitirão ao sujeito agir no meio social e cultural em que está inserido, o mediador precisa atuar na Zona de Desenvolvimento Proximal, tendo como ponto de partida os conhecimentos do aprendiz (VYGOTSKY, 1989).

\section{Demandas por conhecimentos necessários à prática pedagógica: conhecimentos sobre as NEE e suas implicações pedagógicas; conhecimentos sobre aprendizagem e desenvolvimento; conhecimentos sobre estratégias pedagógicas adequadas às necessidades dos alunos; como ensinar em sala de aula inclusiva; como ensinar alunos com deficiência intelectual}

[...] mas precisamos entender tudo que for preciso entender a respeito dessa NEE, pra saber lidar melhor; saber só o nome não resolve, mas o que é, de onde veio... e saber realmente quais são as possibilidades de aprender a ler e escrever, existe? Quais são? De que forma fazer? (PE)

[...] queria ter mais informações na questão do desenvolvimento, desenvolvimento humano. (PC)

[...] estão todos num nível cognitivo avançado e existe uma grande dificuldade, grande, com AE, por conta disso, por conta das exigências dela, tem o déficit cognitivo e não tem como, pelo menos até agora eu tenho grande dificuldade de trabalhar com ela e eu não vejo como AE acompanhar esta turma de quarta série. (PE)

As professoras sentem necessidade de ressignificar e redimensionar suas práticas em sala de aula, qualificando-as e, para isso, necessitam: construir um quadro de referências conceituais que as ajudem a reconhecer seus alunos, evidenciando 
os tipos de mudança necessária no ensino; dissipar dúvidas a respeito do que e de como ensinar aos educandos com NEEs; assegurar boa disposição do espaço físico da sala; participação dos alunos e estruturação cooperativa de grupos, e aprender sobre as possibilidades didáticas para alunos com deficiência intelectual.

\section{Categorias e subcategorias do eixo 3: demandas dirigidas ao psicólogo escolar}

No processo de investigação, nesse eixo temático, emergiram quatro categorias e suas respectivas subcategorias como serão demonstradas a seguir.

\section{Acolhimento: escuta psicológica e suporte}

Esta categoria refere-se à necessidade de um espaço, no contexto escolar, onde os professores possam expressar suas angústias diante das dificuldades para se comunicar, se relacionar ou trabalhar com alunos que apresentem NEE, e onde favoreça sua preparação emocional para lidar com uma nova realidade: ensinar com qualidade alunos com NEEs. Os episódios abaixo ilustram esse posicionamento.

[...] ressalto também a importância desse trabalho (do psicólogo) ser direcionado... è à disponibilidade para nos ouvir, escutar nossas angústias. (PB)

[...] e até eu preciso de psicólogo! Porque às vezes eu fico assim, agoniada pra resolver logo uma coisa, eu quero que a menina $\mathrm{AD}$ já saiba logo; agora como é que eu faço. (PD)

Desse modo, é preciso construir um lugar de interlocução coletivo para circulação dos sentidos que os educadores atribuem a este não saber, mediando processos relacionais e intersubjetivos, tendo em vista a ressignificação dos discursos instituídos e a construção e apropriação de novos sentidos.

\section{Avaliação Psicológica: avaliação para identificação, caracterização e encaminhamento; avaliação das condições que produzem a queixa escolar}

[...] Poderia colaborar de como eu posso ajudar mais aquela pessoa, porque o psicólogo é especialista para uma análise do diagnóstico, numa coisa invisível, cuida do interno e seu reflexo no externo... Ele vê mais a alma daquela pessoa, o interior mesmo, não a parte física, ele vê o individuo. (PF)

[...] Por exemplo: trabalhando com um psicóloga aqui na escola eu ia estar sabendo...como é que $\mathrm{AB}$ pode ter avanços e como é que ela não pode; o porquê que ela chegou ali; como ela pode avançar e como ela não pode, o psicólogo, por ele estar presente ali, ele estaria me apoiando nisso, dando essa base pra mim. (PB)

[...] No tempo do intervalo a professora me pergunta de que modo ela poderia abordar $\mathrm{AA}$, pois a aluna não conversa, não 
fala nada. Percebo sua angústia, falo que o tempo que observei foi muito pequeno, mas questiono se ela já observou AA no recreio, sua relação com sua única amiga, se já tentou descobrir sobre o que falam e seus interesses. Ela informa que não. (DC220/04/2011)

Observa-se a ausência de referências aos encaminhamentos para outros profissionais. O diagnóstico solicitado por algumas educadoras é entendido, segundo uma perspectiva clínica, com base subjetivista e idealista, desconsiderando a base material, objetiva e relacional na constituição dos sujeitos e, excluindo os processos e as práticas educativas como possíveis participantes na produção e manutenção dos comportamentos apresentados pelo aluno com NEE na escola. As falas sugerem a compreensão de que o psicólogo conhece mais a respeito dos sujeitos da educação especial do que os pedagogos.

\section{Comportamentos e emoções em sala de aula: como lidar com dificuldades emocionais e problemas comportamentais dos alunos com NEE; como favorecer a disciplina em classe}

[...] Eu queria saber lidar com a tristeza de um aluno especial. A tristeza de um aluno especial é diferente, porque o outro sabe passar para a gente o que está acontecendo, o que ele está passando, o que ele está sentindo, mas o aluno especial não, ele não sabe expressar. [...] No caso de AF, quando ele chega agressivo, ou muito triste, parece que está angustiado... Naqueles dias eu gostaria de ter a colaboração do psicólogo para analisar ele. Eu gostaria de receber a contribuição para que eu pudesse analisar $\mathrm{o}$ aluno. (PF)

[...] Novamente a professora não planejou nada para o tempo de espera, que durou aproximadamente $30 \mathrm{~min}$. Naturalmente as crianças ficavam cada vez mais agitadas. Após lancharem, demorou alguns minutos para que a professora conseguisse começar os trabalhos, o que só ocorreu às 9 horas. (DC2 04/05/2011)

[...] Ao circular pelas carteiras e atender as solicitações das crianças, observo que a tarefa está acima de suas possibilidades; elas não lêem ainda, nem se lembram das orientações da pro. (DC2 04/05/2011).

A tristeza, por vezes, é percebida como intrínseca à condição dos alunos com NEEs, desconsiderando que os problemas emocionais dos estudantes com ou sem NEE podem ser evidenciados, se manifestarem ou ainda serem produzidos na escola. Há insegurança quanto aos procedimentos adequados para lidar com o aluno que se mostra agressivo em sala e com a turma. As observações explicitaram a presença da indisciplina em três classes, evidenciaram as implicações do comportamento das educadoras e de sua proposta de trabalho na produção dessa indisciplina e o seu impacto junto a alunos com NEE. 
Práticas pedagógicas: colaboração no planejamento do ensino; suporte em sala de aula; atividades regulares de formação

[...] Acho que seria interessante o profissional de psicologia nos momentos de planejamento na escola e se fosse possível até mesmo na sala de aula, pra presenciar um momento desses e dar esta orientação de como lidar com aquilo. (PE)

[...] Contribuir com encontros regulares para trocas de experiências e a formação mesmo do professor. (PA)

[...] Acompanhando, uma ou duas vezes em sala de aula seria bom. [...] O Núcleo da SMED poderia ser mais atuante. Eu acho que o professor e o psicólogo atuando juntos, um iria ajudar o outro, entendeu? (PC)

As demandas relativas ao planejamento devem ser ressignificadas pelo psicólogo, que pode subsidiar o professor acerca da importância de sua mediação nos processos de ensino e favorecer a disseminação de experiências educativas bem sucedidas (BARBOSA; MARINHO-ARAÚJO, 2010). O psicólogo pode contribuir com o aperfeiçoamento profissional contínuo e realizar observações em sala de aula para identificação dos problemas ligados à aprendizagem e ao comportamento e sugerir alternativas de solução, como prevê a literatura em Consultoria Colaborativa (IDOL; WHITECOMB-PAOLUCCI; NEVIN, 2000).

\section{Conclusões}

Os resultados do presente estudo corroboram posições de teóricos da área quando afirmam que a simples inserção de alunos com NEE em classes comuns do ensino regular não assegura aprendizagem, nem viabiliza trocas sociais e simbólicas satisfatórias. Acredita-se que as demandas dos professores devam ser respondidas pelos poderes públicos, uma vez que cabe ao Estado o controle dos recursos financeiros, das decisões políticas e a responsabilidade pelo oferecimento do ensino de qualidade para todos. É necessário, entre outros aspectos, investir na qualificação dos educadores para uma atuação mediadora mais competente, ampliar e diversificar a equipe da educação especial do município ,e ampliar ou rever seu modelo de intervenção junto aos diversos atores da comunidade escolar, a fim de responder satisfatoriamente às necessidades formativas, de apoio psicológico, de suporte e orientação às práticas pedagógicas dos educadores.

\section{Referências}

AMADO, J. Técnica da análise de conteúdo. Referência. Revista de Educação e Formação em Enfermagem (E.S.E. Dr. Ângelo da Fonseca-Coimbra), n. 5, p. 53-63, 2000.

ANACHE, A. Reflexões sobre o diagnóstico psicológico da deficiência mental utilizado em educação especial. Anais. 24르 Reunião anual da Anped. Caxambu, 2001.

ANACHE, A.; MITJÁNS, A. Deficiência mental e a produção científica na base de dados da CAPES: o lugar da aprendizagem. Pesquisas sobre deficiência mental. In: Revista semestral da Associação Brasileira de Psicologia Escolar e Educacional (ABRAPEE). Campinas: v. 11, n. 2, 2007. p. 253-274. 
BARBOSA, R. M.; MARINHO-ARAÚJO, C. M. Psicologia escolar no Brasil: considerações e reflexões históricas. Estudos de Psicologia, Campinas, v. 27, n. 3, p. 393-402, jul./set. 2010. Disponível em: 〈http:// www.scielo.br/pdf/estpsi/v27n3/1l.pdf). Acesso em: 02 mar. 2011.

BRASIL. Conselho Nacional de Educação (CNE). Resolução № 4 CNE/ CEB de 2 de outubro de 2009. Institui Diretrizes Operacionais para o Atendimento Educacional Especializado na Educação Básica - Modalidade Educação Especial Resolução. Diário Oficial da União, Brasília, 5 out. 2009.

Instituto Nacional de Estudos e Pesquisas educacionais Anísio Teixeira (INEP). Censo Escolar 2010. Resumo Técnico. Disponível em: 〈http://portal.mec.gov.br/index.php?option=com_content\& view=article\&id=16179>. Acesso em: nov. 2011

BRIDI, F. R. S.; BAPTISTA, C. R. Deficiência mental e pesquisa: atualidades e modos de conhecer. In: IX SEMINÁRIO DE PESQUISA EM EDUCAÇÃO DA REGIÃO SUL , 2012, Caxias do Sul. Anais. Caxias do Sul, UCS, 2012.

CARVALHO, R. E. Removendo barreiras para a aprendizagem. Porto Alegre: Mediação, 2000.

Com os pingos nos “is”. Porto Alegre: Mediação, 2004.

COLNAGO, N. A. S. Orientação familiar: estratégias de intervenção para pais de crianças com síndrome de Down. In: MENDES, E. G.; ALMEIDA, M. A.; HAYASHI, M. C. P. I. (Org.). Temas em educação especial: conhecimentos para fundamentar a prática. Araraquara: Junqueira Martins, 2008.

FERREIRA, J. R. Educação especial, inclusão e política educacional: notas brasileiras. In: RODRIGUES, D. A. (Org.). Inclusão e educação: doze olhares sobre a educação inclusiva. São Paulo: Summus, 2006. p. $85-113$.

FREITAS, S. N. Considerações acerca da produção de artigos científicos em educação especial: uma análise da Revista Educação Especial CE/UFSM. In: MENDES, E. A.; ALMEIDA, M. A.; HAYASHI, M. C. P. (Org.). Temas em educação especial: conhecimentos para fundamentar a prática. Araraquara, S.P: Junqueira Martins, 2008.

IDOL, L.; PAOLUCCI-WHITECOMB, P.; NEVIN, A. Collaborative consultation. Austin: PRO-ED, 2000.

JESUS, D. M. Formação de professores para inclusão escolar: instituindo um lugar de conhecimento. In: MENDES, E. A.; ALMEIDA, M. A.; HAYASHI, M. C. P. (Org.). Temas em educação especial: conhecimentos para fundamentar a prática. Araraquara: Junqueira Martins, 2008.

LAGO, D. O reflexo da política nacional de inclusão no município pólo de Vitória da Conquista, Bahia. 2010. 140f. Dissertação (Mestrado em Educação Especial) - Universidade Federal de São Carlos, São Carlos, 2010. Disponível em: 〈http://www.dominiopublico.gov.br/pesquisa/DetalheObraForm.do?select_action=\&\&co_obra=187747). Acesso em: 5 ago. 2011.

LIMA, R. S.; MENDES, E. G. Políticas Nacionais para a Educação das Pessoas com Deficiência. In: SIMPÓSIO INTERNACIONAL O ESTADO E AS POLÍTICAS EDUCACIONAIS NO TEMPO PRESENTE, 4.; 2008, Uberlândia. Anais... Uberlândia: Universidade Federal de Uberlândia, v. 1., 2008, p. 1-17.

MENDES, E. G. Desafios atuais na formação do professor em educação especial. Revista Integração, Brasília: MEC / SEESP, ano 14, v. 24, p. 12-17, 2002.

A radicalização do debate sobre inclusão escolar no Brasil. Revista Brasileira de Educação, v. 11, n. 33, 2006. Disponível em: 〈www.scielo.br/pdf/rbedu/vlln33/a02vll33.pdf〉. Acesso em: out. 2009.

. Caminhos da pesquisa sobre formação de professores para a inclusão escolar. In: MENDES, E. A.; ALMEIDA, M. A.; HAYASHI, M. C. P. (Org.). Temas em educação especial: conhecimentos para fundamentar a prática. Araraquara: Junqueira Martins, 2008.

Revista Educação Especial | v. 27 | n. 48 | p. 27-40 | jan./abr. 2014

Santa Maria

Disponível em: <http://www.ufsm.br/revistaeducacaoespecial> 
Histórico do movimento pela inclusão escolar. In: Inclusão marco zero: começando pelas creches. Araraquara: Junqueira Martins, 2010.

et al. Formação de professores na perspectiva da inclusão escolar: uma nova proposta de formação. In: MENDES, E.; ALMEIDA, M. A. (Org.). Das margens ao centro: perspectivas para as políticas e práticas educacionais no contexto da educação especial inclusiva. Araraquara: Junqueira \& Martins, 2010.

MIRANDA, T. G. Formação docente continuada: uma exigência frente à proposta da educação inclusiva. In: MARTINS, L. A. R. et al. (Org.). Prática inclusivas no sistema de ensino e em outros contextos. Natal: EDUFRN, 2009.

PEREIRA, R. M.; ANDRADE, E. P.; ANJOS, H. P. A inclusão escolar do ponto de vista dos professores: o processo de constituição de um discurso. Revista Brasileira de Educação, Rio de Janeiro, v. 14, n. 40, jan./ abr. 2009.

PREFEITURA MUNICIPAL DE VITÓRIA DA CONQUISTA (PMVC). Secretaria Municipal de Educação. Diretrizes para a educação inclusiva. Vitória da Conquista: SMED, Núcleo Pedagógico, 2007.

ROCHA, M. L.; SOUZA, M. P. R. Políticas Educacionais: legislação, formação profissional e participação democrática. In: CONSELHO FEDERAL DE PSICOLOGIA. CRP Ano da Psicologia na Educação: textos geradores. Brasília, 2008. Disponível em: ‘http://www.pol.org.br/pol/export/sites/default/pol/publicacoes/ publicacoesDocumentos/textos_ano_psicologia_educacao.pdf〉. Acesso em: 16 mar. 2011.

SIEMS, M. E. R. Educação especial em tempos de educação inclusiva: identidade docente em questão. São Carlos: Pedro e João editores, 2010.

VELTRONE, A. A Inclusão escolar do aluno com deficiência intelectual no estado de São Paulo: identificação e caracterização.Tese (Doutorado)-Programa de Pós Graduação em Educação Especial, Centro de Educação e Ciência Humanas, Universidade Federal de São Carlos, São Carlos, 201l. Disponível em: 〈http://200.136.241.56/htdocs/tedeSimplificado/tde_busca/arquivo.php?codArquivo=425l.〉 Acesso em: $07 / 2013$

VYGOTSKY, L. S. Pensamento e linguagem. São Paulo: Martins Fontes, 1989.

\section{Notas}

${ }^{1}$ Parte da Dissertação de Mestrado intitulada Análise de demandas decorrentes da educação inclusiva e das possibilidades de atuação do psicólogo escolar, realizado na Universidade Federal de São Carlos - UFSCar.

${ }^{2}$ No município em questão o "cuidador" compõe a equipe funcional da escola e tem como função: acolher o educando com NEE, ajudá-lo em atividades da vida diária, participar de brincadeiras e jogos promovendo a interação deste com os pares, atendendo as orientações do professor.

\section{Correspondência}

Selma Norberto Matos - Universidade Estadual do Sudoeste da Bahia, Departamento de Filosofia e ciencias humanas. Estrada do Bem Querer, Km 04, Universitário CEP: 45083-900 - Vitoria da Conquista, Bahia, Brasil

E-mail: selmanmatos@gmail.com - egmendes@ufsca.br

Recebido em 25 de abril de 2013

Aprovado em 24 de julho de 2013 